\title{
Critical Review
}

\section{Aristotle on False Reasoning: Language and the World in the Sophistical Refutations}

\author{
SCOTT G. SchreIBER
}

Albany: State University of New York Press, 2003. Pp. xvi +248. Hardcover: ISBN 0-794-5659-5, US\$68.50; paperback: ISBN 0-7914-5660-9, US\$22.95.

\section{Reviewed by George Boger}

\section{Overview}

Schreiber's examination of Aristotle's treatment of the 'traditional' fallacies in Sophistical Refutations $(S R)$ is well worth the attention of logicians, philosophers, argumentation theorists, and classicists who desire a better understanding of Aristotle's ancient accomplishments relating to logic and argumentation. While Schreiber occasionally engages contemporary argumentation theorists ${ }^{!}$about fallacious reasoning and their assessment of A ristotle, his principal concern is historical and not directly to resolve modern problems concerning a typology of mistakes. Thus he early establishes the error of reducing all sophistical argumentations to linguistic problems. Nevertheless, because he emphasizes the non-formal aspects of fallacious reasoning, he might strike a chord with argumentation theorists. Still, he does not aim to accommodate modern predilections but to make clear Aristotle's "philosophical justification ... for his classification of fallacies" (xiv), which he successfully argues is "principled and nonarbitrary" (7). He accomplishes this through numerous analyses of each kind of fallacy according to a comprehensive method that includes: (1) considering Aristotle's understanding of the relationship between language and nature; (2) embracing Aristotle's notion of explanation; (3) recognizing the role Aristotle assigns to resolution for categorizing a fallacy; (4) working with the definitions of a syllogism and a refutation; and (5) invoking the principle of parsimony implicitly operative in Aristotle's system of categorization. The principle of parsimony helps to sift out problems relating the discussions in $S R$ to discussions in Topics, On Interpretation, Categories, and Rhetoric. Accordingly, Schreiber carefully 'parses' each of Aristotle's examples and nicely accommodates their re-presentations to a modern English-speaking reader. This is no mean accomplishment, and Schreiber in the process displays familiarity with the ancient Greek language. However, while in general sympathy with Aristotle, he is not an apologist for his errors. Such close examination of Aristotle's discussion of fallacious reasoning, which Schreiber calls "false reasoning", reveals some important lapses in his thinking. In particular, he notices some discrepancies in Aristotle's treatment of the fallacies in $S R$ and between $S R$ and other treatises in the Organon. As a consequence, working interpretively within Aristotle's philosophy,

(C) Informal Logic Vol. 23, No. 1 (2003): pp. 77-90. 
he makes some important adjustments to his categorization while not discounting the cogency of his determinations. In this sense, then, Schreiber contributes to our knowledge of Aristotle's logic while not running afoul of becoming an 'Aristotelian' in the vein of so many contemporary authors who misrepresent Aristotle's logic in introductory textbooks.

Schreiber has organized his discussion of the fallacies along the lines established by Aristotle as modified by his interpretive posture. After a short preface (xiii-xv) and an informative introduction (1-7) where he outlines his approach, the book is divided into three parts of nine chapters. Part 1 examines the fallacies due to language: Chapter 1 treats the power of names $(11-18)$; Chapter 2 , homonymy and amphiboly (19-36); Chapter 3, form of expression (37-54); and Chapter 4, composition, division, and accent (55-76). Part 2 consists in a single chapter on resolving false arguments (79-93). Part 3 examines the fallacies falling outside of language: Chapter 6 is on begging the question and non-cause as cause (97-112); Chapter 7 treats accident and consequent (113-139); Chapter 8, secundum quid (141-151); and Chapter 9, many questions (153-166). There is a brief section entitled "Conclusion and Summary" that acts as a kind of final chapter (167171).In addition there are four short but informative appendices (173-190) treating, respectively, paralogisms in Aristotle, words and counters-Platonic antecedents, Aristotle on kúplov predication, and Platonic and Academic background to secundum quid. Notes (191-232) are gathered as endnotes and followed by a small bibliography and an index of names. There is an only modestly useful subject index: there are no entries, for example, for 'protasis', 'proposition', 'premise', 'multiple reference', 'language convention' and 'relevance', all of which Schreiber treats, nor for many of his subsection headings; however, the contents (vii-x) could serve as an auxiliary index. In addition, there is no index of passages cited, which are numerous and which appear in the endnotes. A glossary of Aristotle's logical terminology would be a nice addition.

\section{Adjustment to Aristotle's categorization}

Schreiber remarks that he was initially provoked by Aristotle's categorical claim that there are only twelve fallacies. He sensibly follows Aristotle to consider ignoratio elenchi generic of fallacious reasoning and not itself a thirteenth fallacy. Following Aristotle, then, to divide fallacies into those due to language and those not due to language, Schreiber takes Aristotle's typology as reproduced in the following table $(4,167)$.

This, of course, is all familiar. Once having established Aristotle's program, he proceeds in Part 1 to examine the fallacies due to language with an express purpose not only to elucidate Aristotle's thinking but also to indicate something problematic with it. He turns to the pivotal section of his discourse in Part 2, where he lays out the interpretive apparatus of his own modified 'Aristotelian' method. This 
False reasoning

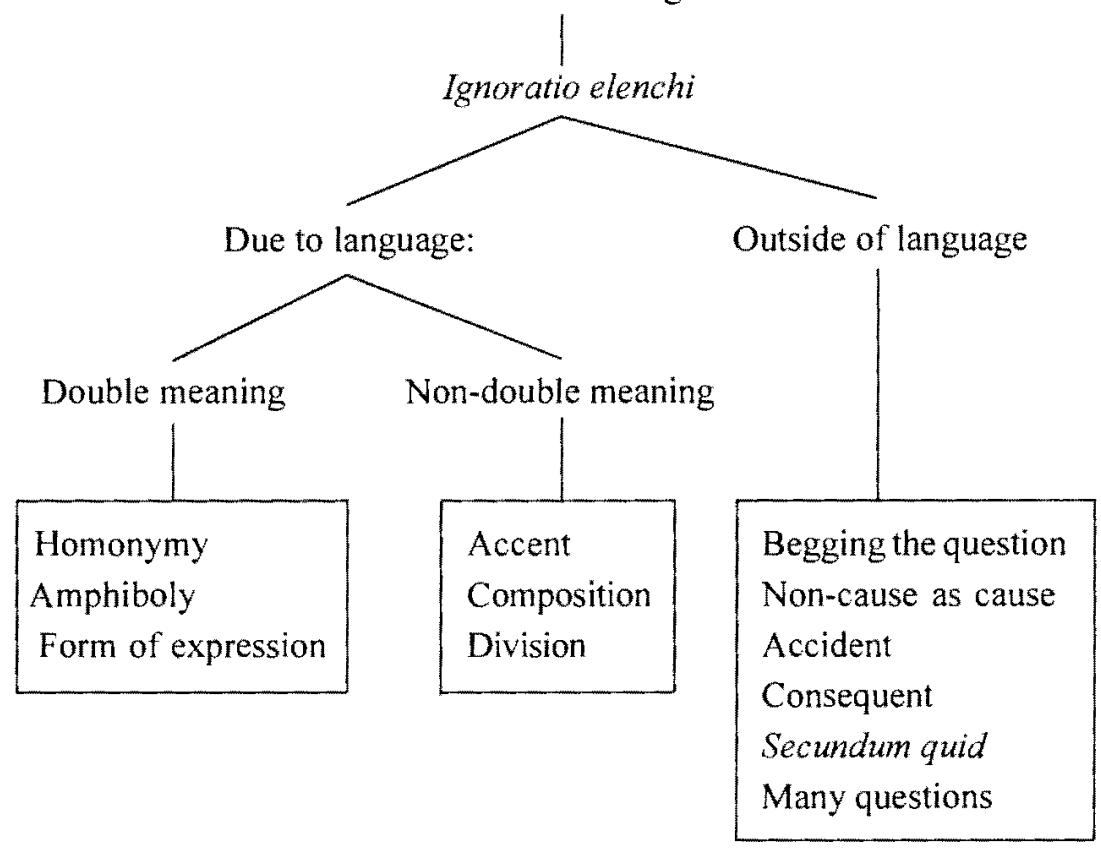

method affords him a vantage point to review and critique each type of fallacy due to language. He proceeds in Part 3 to examine the fallacies outside of language using the method established in Part 2. After completing these analyses, he presents his adjustment to Aristotle's categorization (171) as reproduced in the table on the next page.

Schreiber's project in Aristotle on False Reasoning is to justify this adjustment to Aristotle's categorization of the fallacies as more faithfully representing both Aristotle's discourse on fallacious argumentation and his incompletely fulfilled intention.

\section{Schreiber's interpretive apparatus}

Schreiber identifies the role Aristotle attributes to the resolution of fallacies as central for understanding Aristotle's typology. This approach, not merely constituting Schreiber's interpretive stance but also an integral part of Aristotle's own method, renders Aristotle's typology intelligible and helps to make sense of variant ascriptions when such ascriptions sometimes appear arbitrary.

Schreiber identifies two principles underlying Aristotle's analytic method: (1) understanding defective reasoning requires understanding the paradigm of nondefective reasoning; (2) understanding itself requires providing causes--in the 


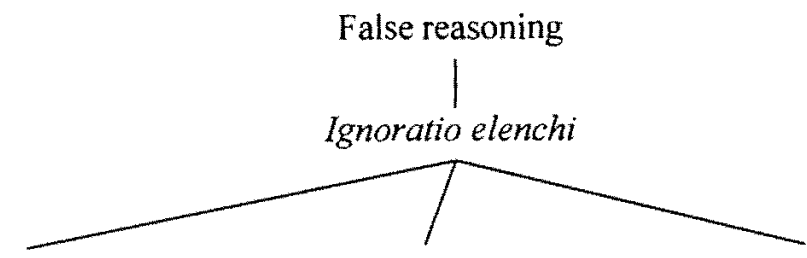

Due to language:

Non-double meaning ${ }^{2}$

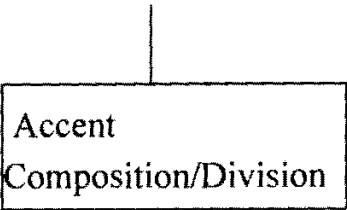

Due to language

Double meaning

Homonymy

Amphiboly

Form of expression

Secundum quid

Multiple reference
Outside of language

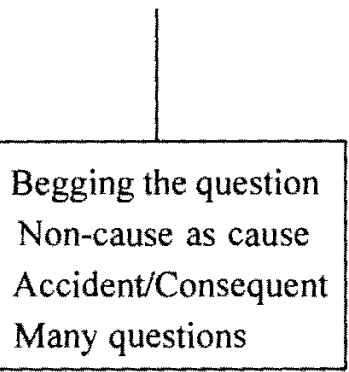

case of reasoning, the causes of both nondefective and defective reasoning. Now, since encountering perplexity motivates the activity of reasoning toward a resolution, a proper resolution must be fully explanatory. And to be fully explanatory, a resolution must explain (1) "why the purported reasoning is not real reasoning", and (2) "why the false reasoning appears to be real reasoning" (81, emphasis added). Schreiber considers the first to be a fairly objective procedure: "reasoning

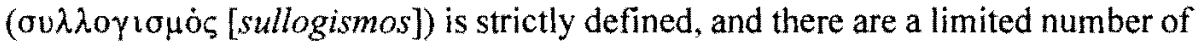
ways to violate that definition" (81). The second he recognizes to be relative to a participant's understanding or misunderstanding of language and nature-just the sources for both correct and incorrect reasoning.

In respect of the definition of a sullogismos, which provides the baseline for argument assessment, Schreiber begins immediately with Aristotle's statement in $S R$. "He defines a syllogism as "an argument in which, when certain things are set down, something different from the things set down follows necessarily by means of the things set down" (1). In an endnote to his rendering "sullogismos' as 'syllogism', Schreiber notes his preference either to transliterate the word as 'syllogism' or to render it by 'reasoning'. In this respect he reverts to the older practice of such translators as Poste, Forster, and Pickard-Cambridge (prior to Barnes' emendations, Princeton 1984). Moreover, he does not restrict its use to denoting only a three-term valid argument as in Prior Analytics. Nor does he translate it by 'deduction', as is now customary in discussions of Aristotle's formal logic and even in Louis-André Dorion's recent French translation (1995), since, as he writes, "not all formally valid deductions constitute syllogisms in Aristotle's sense" (191). Schreiber continues next to distinguish various kinds of syllogism namely, demon- 
strative, dialectical, peirastic, and eristic. He also refers to ignoratio elenchi in this connection. He does not make reference here, and only sparingly when he treats many questions, to what a proposition ( $\pi \rho \delta^{\alpha} \hat{\alpha} \sigma \iota \zeta$; protasis) is, and this is an important omission. Still, he cites Aristotle's definition of a refutation and recognizes it to be a syllogism/reasoning to the contradictory of a given proposition. He then extracts and gathers the features of a refutation as part of his paradigm for assessing the error of a fallacy $(88,144)$. A refutation is a syllogism in which: (1) premises do not include the conclusion; (2) a conclusion follows necessarily from the premises; and (3) a conclusion denies one and the same predicate affirmed in the premises. In respect of this last requirement, the predicate denied must be: (3a) the thing signified, not just the name; ( $3 b$ ) the thing signified by the name affirmed in the premises; and $(3 c)$ the thing qualified in precisely the same way as it was affirmed in the premises. Now, while a fallacy can be resolved relative to a person or relative to the argument, Aristotle preferred the resolution relative to the argument since this resolution is more widely applicable to other false arguments of the same kind. Schreiber seems to take Aristotle to mean by 'relative to the argument' that an error is objectively located in a 'violation' of syllogistic, that is, of deductive, reasoning as well as in holding mistaken beliefs about nature.

Next, in taking a charitable tack toward understanding Aristotle, Schreiber invokes a principle of parsimony-that "if one resolution schema S determines two classes of fallacy where another resolution schema $T$ determines one class, then T is better than S" (85). Schreiber takes it as implicitly operative in Aristotle's analyses and not merely his own interpretive device. The utility of this principle consists in its ability to specify "the defining characteristics of the infimae species of false reasoning" (85). Applying this principle helps to identify how Aristotle categorized each fallacy and thus to make sense of what often appear to be arbitrary assignments; it goes far to account for the cogency of Aristotle's categorization.

Finally, a crucial part of Schreiber's interpretive apparatus consists in his appreciation of the conventional nature and epistemic role of language to represent the world in human cognition. While he does not treat this matter extensively anywhere, he treats it sufficiently well in Chapter 1 and later in Appendices 2 and 3 for his readers to grasp his intention. Schreiber locates the sources of fallacious reasoning in precisely the places where the cogent reasoning that leads to knowledge of the world originates-in the gap between knowing and being that language mediates.

\section{Aristotle's principal error}

Throughout his discourse Schreiber aims to preserve Aristotle's assessment of fallacious reasoning; he believes his adjustments are entirely commensurate with Aristotle's thinking. Aristotle's principal mistake, while he was nevertheless very 
attuned to a conventional notion of language and the multivocity of words in their relationships to things, was to fail to recognize the multivocity of "multivocity." Schreiber writes:

Given, then, the unlimited number and unknowable nature of individuals, names possessing the power of multiple signification become necessary epistemological tools for understanding. But this sort of multiple signification is nothing more than the power of common predicates to signify multiple individuals. It does not require that common predicates signify multiple $k i n d s$ of individuals. This latter phenomenon, however, turns out to be one of the chief culprits among Aristotle's examples of fallacies based on linguistic double meanings.

The power of multiple signification includes for Aristotle both (non-homonymous) universals that apply to multiple individuals of the same definition and homonymous names that signify things having different definitions. The former is a necessary feature of language based on the nonisomorphic relationship between names and things signifiable, while the latter is a purely contingent feature of any given language. Yet Aristotle sometimes conflates the two. In both types of false reasoning, those generated by universals having references to multiple individuals and those generated by universals signifying different kinds of individuals, there is a failure to signify the same thing (whether individual or kind) by the same word or phrase, and this seems to have been what impressed A ristotle more than the difference between the two (17, emphasis added).

The power of names, in one respect, consists in their having multiple signification, that is, a given universal word can signify (1) many different individuals falling under that universal as well as (2) that universal itself under which the individuals fall. This is a necessary and inevitable epistemic feature of language. In another respect, the power of names can consist in a word signifying different kinds of individuals rather than different individuals of the same kind. In short, while Aristotle recognized an essential feature of language to possess words signifying universals that refer to the individuals under them-and a feature that locates a source of fallacious reasoning-he missed that such words also signify the universal itself and different individuals of the same kind. "Aristotle would be better served by explicitly differentiating from semantic multivocity a second species of double meaning, namely, where one and the same signifier makes reference to multiple individuals under one universal signifier" (170). According to this approach, we can understand Schreiber's addition of "multiple reference" as a fallacy due to language where double meaning is problematic (170-171).

\section{Fallacies due to language}

Aristotle's treatment of homonymy and amphiboly in $S R 4$ is not especially problematic: an ambiguity due to homonymy occurs when the same name has seman- 
tic double meaning apart from syntax; an ambiguity due to amphiboly when the same phrase having semantic double meaning because of its constituent names having double syntactic roles. A problem arises when in $S R 17$ A ristotle confuses the two, even having difficulty classifying a given case. In the 'double Coriscus' case, for example, Aristotle vacillates between the confusing of two different individuals of the same kind having the same name (amphibolous because of syntax) and the confusing of two different kinds signified by the same name (homonymous). In the case of form of expression, Schreiber follows the usual practice of taking these fallacies to be instances of category mistakes, but he extends this approach to include other confusions arising from not properly understanding nature. Sometimes it is difficult to differentiate form of expression from homonymy and amphiboly, Again we encounter Aristotle's conflating notions of multivocity, in this case not sufficiently recognizing names having the same inflections or the same syntactic positions signifying different kinds of things.

In the case of composition and division, linguistic fallacies not involving double meaning, Schreiber rebuts the conventional understanding that these fallacies involve confusions of parts and wholes (which would place it outside fallacies due to language), except when the parts/whole problem involves the constituent parts of a proposition. Still, this fallacy does not involve double meaning, and thus it is not reducible to either homonymy or amphiboly. Schreiber shows that Aristotle did not here really distinguish two fallacies but rather two "opposite" perspectives of the same linguistic problem-now viewed from the vantage point of fallacy resolution. Moreover, Schreiber picks up on Aristotle's closely linking the fallacies of composition and division with those of accent to affirm that these fallacies are best understood as arising in the transition from an oral to a literate language--they "stand as monuments to the changes in Greek orthography beginning in the fourth century" (68).

This emphasis on the utterance rather than the written proposition is the major means by which Aristotle distinguishes between errors due to Accent, Composition, and Division and those due to double meaning (homonymy, amphiboly, and form of expression). In the former cases, one fails to recognize that a unique signifier is being used with multiple significations. In the latter cases, one fails to recognize that two unique signifiers, each with univocal signification, are being treated as one signifier. In the one, the appearance of syllogistic validity derives from ignorance of multivocity. In the other, the appearance of syllogistic validity derives from ignorance of what individuates a signifier. These different sources of the false appearance are Aristotle's chief means of distinguishing between fallacy types. Isolating these sources is the task of resolving the fallacy. (75-76)

Schreiber attributes to Aristotle an understanding that each fallacy due to language derives from violating the refutation-requirement of having a conclusion that denies one and the same predicate affirmed in a premise. 


\section{Fallacies not due to language}

Schreiber represents Aristotle as understanding fallacies not due to language to be violations of the requirements of a syllogism in its refutation role. He maintains that Aristotle considered begging the question to violate the requirement that the conclusion not already be included among the premises, that each of non-cause as cause, accident, consequent, and many questions violates the requirement that a conclusion follow logically from the premises. However, he considers secundum quid to violate the requirement that the predicate denied in the conclusion must be the same predicate affirmed in the premise-that the thing be qualified in the denial in the same respect that it was affirmed in the premise. This fallacy involves mistaken beliefs about the way names and expressions relate to the things they signify and thus it combines errors about language and errors about natureindeed, deceptive ways of speaking may produce mistaken beliefs about nature. Schreiber argues that secundum quid properly belongs among the fallacies of double meaning due to language. He also alters Aristotle's distinguishing accident and consequent in much the same manner as he adjusts Aristotle's treatment of composition/division-accident/consequent is one fallacy because each instance employs the same kind of resolution, namely, showing by counterexample that not all predicates belong equally to things and their accidents. In the case of non-cause as cause, Schreiber notes that Aristotle's definition of reasoning has a built-in relevance requirement, that the error lies in a participant's "ignorance of which things are relevant explanations of non-self-explanatory facts" (112). This is not a formal feature of invalidity, but a participant's epistemic failing about ontology. This failure is also a signature for cases of accident/consequent where someone mistakes the terms in the premises to signify things "indistinguishable and one in substance." In the case of many questions, Schreiber makes only a cursory reference to its violation devolving to ignorance of what a protasis is, something Aristotle considers important in $S R 6$ along with ignorance of what a refutation is in $S R 6$ and earlier in $S R 5$. Schreiber emphasizes the error as related to mistaken beliefs about nature. The two forms of many questions, disjunction and conjunction, consist in errors in predicating, respectively, what belongs to a whole as also belonging to each of its parts (the real locus of the parts/whole fallacy misascribed to composition/division) and disjunctively offering an irrelevant premise as explanatory of the conclusion.

Since argumentation theorists have devoted considerable attention to begging the question, perhaps Schreiber's treatment of this fallacy can illustrate Aristotle': notion of correct reasoning and something of his notion of a paralogism. Discus sion has often focused on the sense in which there exists 'fallacious reasoning' From the vantage point of modern logic there is, strictly speaking, no fallacy, tha is, no violation of entailment or validity per se. Schreiber notes the restriction Aristotle places on deductive argumentation that distinguish his notion from that $\mathrm{c}$ 
I modern logician. The error in begging the question is not formal per se, but spistemic; and this error devolves to a mistaken belief about nature. Schreiber otes that in Prior Analytics (he makes references in this connection to Posterior Analytics only in endnotes) Aristotle considers a demonstration ( $\grave{a} \pi \delta ́ \delta \epsilon \downarrow \xi l \varsigma)$, which $s$ a syllogism, to have epistemic requirements, namely, that its premises be better known and prior to the conclusion. He leaves unstated that these premises must also be known to be true. The requirement that such propositions be better known and prior to the proposition in the role of conclusion means that the premise propositions must be known through themselves. Such propositions are, then, self-explanatory and not, which Schreiber does not mention, mediated-they are $\alpha \dot{\mu} \epsilon \sigma o v$, that is, they are not the results of syllogistic reasoning but its starting points or first principles. In fact, as Schreiber does remark in an endnote (214), the fallacy is properly named "asking the original point" or "assuming the original point". He then lists five ways that a case of begging the question might arise, all of which devolve to a epistemic requirement of demonstrative reasoning. In a brief section relating begging the question to immediate inferences, or certain logical equivalences, Schreiber remarks that someone's "not recogniz[ing] the natural epistemic equivalences of logical equivalences" (105) makes that participant vulnerable to this fallacy. The putative defect in reasoning lies not in validity per se but in the Aristotelian requirement that a syllogistic conclusion be a proposition whose terms have been mediated through the premise propositions. Schreiber does not incorporate this notion into his assessment of $S R$.

\section{Concluding remarks}

Schreiber early makes clear, while nevertheless largely following conventional wisdom about assessing fallacious reasoning, that guarding against false reasoning involves beliefs not just about the "mechanics of proper logical form ... [but also about] the right meta-logical and metaphysical beliefs" (xiii). Indeed, his assessment of fallacious reasoning decidedly shies from a formal logical analysis. Sophistical reasoning naturally involves various appearances. There are: premises that appear to be what they are not; arguments that appear to be valid but are invalid; valid arguments that appear to be relevant but are not (2). Resolving such appearances requires discovering certain false beliefs, in particular, those about: the parts of language itself; the relationship language has to the realities it signifies; and the non-linguistic world outside of language signified by language ( 6 ; cf. 150-151). Schreiber does not succumb to psychologistic explanations of these appearances but repeatedly locates their sources in mistaken beliefs about nature. We might recognize a leitmotif of his book that "logic, as a general study of reasoning, is not metaphysically neutral for Aristotle" (7). This notion of 'metaphysical partiality' chimes again at the very close of his discourse that logic "is not a metaphysically neutral activity" (171). 
A particularly attractive feature of Schreiber's discourse in this connection, as his subtitle suggests, is treating fallacious reasoning not only against the standards of correct reasoning but also by understanding correct reasoning as itself grounded in nature. This understanding requires excursions into ontology for two projects: (1) to ascertain the truth or falsity of a given proposition and (2) to ascertain the validity or invalidity of a given argument. Schreiber, however, does not especially explicate this theme; his study is more practically disposed and not itself a work in the philosophy of logic and ontology. Still, he mentions or suggests at important junctures-for example, when elucidating the notion of fallacy resolution, in appendix 3 on kuṕrov predication, and when comparing Protagoras on solecismthe notion that language reflects in consciousness realities existing independently of consciousness and that grasping correct reason, analogous to grasping the truth and falsity of a proposition, has an ontic underpinning. Aristotle, he remarks, considered language a human convention for understanding nature. Although nowhere ascribing a correspondence perspective to Aristotle, Schreiber surely attributes such a view to Aristotle for understanding his accomplishments in $S R$. This theme resonates in his explaining and resolving fallacious reasoning in both its objective and participant relative respects. In fact, he concludes that all the fallacies, with the exception of accent and composition/division, derive their persuasive appearance wholly or partly from some sort of extralinguistic misconception." "Because the ability to reason correctly is dependent on the ability to distinguish true from false argumentation, it follows that, for Aristotle, proper reasoning requires a proper metaphysics" (170-171)-that is, an epistemology grounded in a proper understanding of nature. Not having the proper ontology necessarily leads to confusing cogent and fallacious argumentations.

[While] Aristotle has not given us the last word either on metaphysics or language ... contemporary logicians should recognize, as Aristotle did, that even our logical intuitions-those beliefs about what constitutes a valid inference that formal systems of natural deduction are designed to capturethemselves are based upon definite ontological presuppositions. Aristotle's general position merits serious consideration. Logic, as the study of reasoning, is not a metaphysically neutral activity. (171)

Argumentation theorists and formal logicians might give this notion more serious consideration.

Schreiber, then, neither aligns himself with traditional formal logicians nor especially with argumentation theorists. He has managed to steer a course between the two and perhaps as a consequence to have established some new ground, consideration of which might move both traditions toward some reconciliation. On the one hand, Schreiber suggests that logic is a part of epistemology, whose project is to establish objective knowledge of the truth or falsity of a given proposition. In this connection, logic treats argumentation formally in respect of determining the validity or invalidity or a given argument as a deductive exercise. On the other hand, he suggests that such a project requires an awareness of its ontic 
underpinning. Objective knowledge of both truth and falsity and validity and invalidity requires grasping them as reflections in cognition of matters objectively independent of cognition. Thus, a formal logician might better grasp the ontic foundation of validity and invalidity as with truth and falsity, and an informal logician might better recognize the traditional formalism underlying study of fallacious reasoning. Demonstrative knowledge requires objective knowledge both of logical consequence and truth and falsity as these unite in argumentation. Schreiber's discussion only suggests this application of his study.

Finally, we indicate some matters that need attention for our improved understanding of $S R$. First, the scholarly community still awaits a fuller understanding of Aristotle's notion of a paralogismos, typically translated by 'fallacy' as Schreiber. Second, Schreiber's notion of a sullogismos is unsatisfactory in light of recent developments. And, third, while he displays familiarity with Greek and generally with logic, his translations of Aristotle's logical terminology need considerable refinement.

Just what counts as a fallacy or a mistake in reasoning is continually discussed among argumentation theorists, less avidly or assiduously among formal logicians. Getting a grip on this matter, of course, is compounded by similar discussions about what counts as an argument or an argumentation, whether cogency is participant relative or context independent, etc.--in short, by discussions about 'good arguments' and 'bad arguments'. When a modern logician turns to assess Aristotle's treatment of fallacious reasoning, and even to his treatment of 'formal logic', he or she is often encumbered by various modern prejudices as well as by mistaken notions of logic. In just this respect, then, we need a clear exposition of how Aristotle understands deductive reasoning, or natural deduction as the case may be, and how he understands an argument not to satisfy deductive rigor. Schreiber has followed the conventional wisdom to consider $S R$ the final section of Topics, thought to be part of an 'earlier logic.' It is customary to consider Aristotle's treatment of the fallacies to be 'informal', since he hardly invokes the formalism evident in his treatment of syllogistic reasoning in Prior Analytics. However,

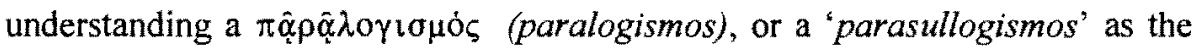
case may be, might require understanding something of the formalism of a sullogismos. There are suggestions of this requirement in $S R$, as indeed the second part of Prior Analytics involves matters relating to $S R$. Schreiber in Aristotle on False Reasoning makes headway on this project as, for example, in (1) his laying out the requirements of a refutation, (2) his brief and insightful appendix 1 on paralogism, and (3) Chapter 5 on resolution. However, grasping fallacious reason-

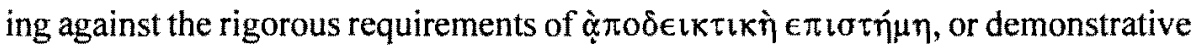
knowledge, would considerably enrich his portrait of a paralogismos. An analogue of this approach concerns the order of writing the two Analytics. Whether the writing of Posterior Analytics antedates that of Prior Analytics, we can still recognize that Posterior. Analytics is informed by his conception of a sullogismos as 
treated in Prior Analytics. Perhaps, then, our understanding of a paralogismos as Aristotle treats it in $S R$ could be informed by grasping how he understands a sullogismos in Prior Analytics. In any case, this matter needs to be worked through more fully as a topic in its own right.

Granting a mutual relationship among the Organon treatises for understanding each of them, we might expect Schreiber's treatment of a sullogismos and its role in resolving sophistical refutations to need some adjustment. His treatment of assessing argumentation seems throughout to waffle on this matter. On the one hand, he downplays syllogistic formalism by turning to semantic and ontological matters, and, on the other hand, he invokes the validity requirement of a refutation (an elenchos), which just is a sullogismos. But he leaves undetermined the connection between the two; thus he leaves undetermined how Aristotle conceived their relationship. Does Aristotle presume an underlying formalism in his assessment of fallacious reasoning? Does Aristotle link semantic considerations to determining the form/pattern of an argument? These are important and eminently interesting matters, clarity on which, albeit principally historical, would benefit formal and informal logicians alike. We can leave open the question about reducing the fallacies to linguistic problems. Nevertheless, it is possible to reduce most of the fallacies-as Aristotle himself suggested when he referred to them as ignorance of what a refutation is and what a proposition is-to violating the rule for mediating terms in 'categorical' logic, the very logic grounded in a substance/attribute ontology as Schreiber so aptly notes. Of course, then, we must better grasp that the form, or pattern, of a proposition and that of the argument consisting in such propositions, has a semantic dimension. While the pattern of a sullogismos, such as, that named "Barbara," is patently obvious, recognizing that a homonymous name in a categorical sentence really constitutes two terms and thus that the one sentence expresses two propositions is not so obvious. The fallacy of homonymy, then, is analyzable as a formal violation-namely, the introduction of a fourth term. Perhaps, then, all the fallacies, save begging the question, introduce a fourth term and thus violate the formal requirement of a sullogismos, which leads to a conclusion that is not a logical consequence of the given premises. While this notion might seem to stretch interpretive license, it will nevertheless strengthen the integrity of Aristotle's accomplishment. This is another worthy avenue for further investigation.

Perhaps the most infelicitous aspect of Schreiber's discussion concerns his translations of Aristotle's 'technical' terminology. Throughout his discourse he uses the following expressions: 'false argumentation', 'false reasoning', 'false refutation', 'false appearance', 'false belief', 'false argument', and each of these has its counterpart of 'real', as in 'real reasoning'. Schreiber translates ' $\psi \in u \delta \delta$ ' $\varsigma$ '

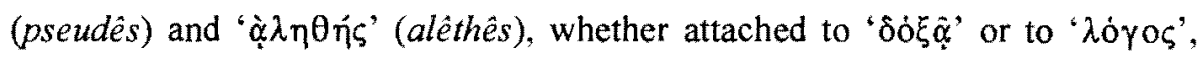

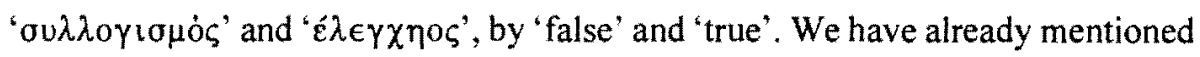
his translating 'sullogismos' by 'syllogism' and 'reasoning'. : 'owever, he not only 
refers to a valid or invalid argument, he also refers to a valid or invalid syllogism and a valid deduction, and this is decidedly not Aristotle's understanding-every sullogismos is valid. Now, while his generally equating an eristic argument with a sophistic argument as paralogisms, and each of these with an apparent sullogismos, is correct, his purpose would be better served to translate 'pseudès' and 'alêthês' by, respectively, 'faulty' or 'spurious' and 'genuine'. Surely when someone thinks or reasons, whether faultily or non-faultily, that person is doing real or genuine thinking. A proposition or belief is true or false, an argument valid or invalid, and an argumentation, which might involve establishing knowledge of validity or invalidity, is either cogent (on the principle of transitivity of consequence) or fallacious. In each case, a participant might have mistaken beliefs as Schreiber so well establishes. He reverts here to earlier translations. Consequently, his manner of expression reflects not consulting recent work on Aristotle's deduction system; nor, it seems, despite his cordial acknowledgment of Dorion's French translation of $S R$, has he absorbed that contribution. Dorion translates 'sullogismos' by 'déduction'. This practice does not nullify his contribution to our understanding of $S R$. However, while his facility with ancient Greek is adequate to explicate parts of $S R$, his handling of the logical terminology raises questions about his logical acumen and thus about his faithfully reproducing Aristotle's meaning. Schreiber needs to work through this matter more carefully.

Schreiber treats other topics that might interest argumentation theorists. There are, for example, his discussion of the monolectical and dialectical aspect of reasoning (although not using these expressions), his discussion of the relationships of syntax and semantics (in respect of Aristotle's understanding and a modern making sense of the fallacies), and his assessing various typologies. His treatment of these topics is informative about Aristotle's thinking and about argumentation. His perspective on typing fallacies according to their resolution is generally convincing. Overall he successfully presents Aristotle as a competent and principled student of fallacious argumentation and shows that studying Aristotle can provide a worthwhile vantage point for assessing modern argumentation. Schreiber's contribution is a nice complement to recent work on $S R$. Indeed, his book can serve as a useful companion to contemporary efforts at translating $S R$ and to continuing studies of that ancient treatise on argumentation.

\section{Notes}

' Argumentation theorist' is used here generally to compass persons working in various trends in modern studies of fallacious reasoning, as well as of good reasoning, and thus to include informal logicians, pragma-dialecticians, critical thinking theorists, and new rhetoricians.

${ }^{2}$ After concluding his discourse, Schreiber qualifies each kind of fallacy in the following ways (171; cf. 169): those due to language without double meaning as involving errors about language both necessary and sufficient for false appearances; those due to language with double meaning 
as involving errors about language necessary but not sufficient for false appearances; and those outside of language as involving errors about ontology sufficient for false appearances.

${ }^{3}$ See, for example, his comments in this respect for each of the fallacies: homonymy and amphiboly (93), form of expression $(51,93)$, begging the question (106), non-cause as cause $(109,112)$, accident/consequent (139), secundum quid (151), many questions (166), and multiple reference (170). However, his treatments of accent and composition/division also seem to involve this principle of explanation (76).

\section{References}

Dorion, L.-A. 1995. Aristote; Les réfutations sophistiques. Paris: Vrin.

Forster, E.S. 1955. On Sophistical Refutations. Cambridge: Harvard University Press.

Pickard-Cambridge, W.A. 1928. Topica and De Sophisticis Elenchis. Oxford: Clarendon Press.

Pickard-Cambridge, W.A. 1984. Sophistical Refutations. In J. Bames, The Complete Works of Aristotle. Princeton: Princeton University Press.

Poste, E. 1987/1866. Aristotle on Fallacies or the Sophistici Elenchi. New York: Garland Publishing.

George Boger Department of Philosophy Canisius College 2001 Main Street Buffalo, NY 14208-1098 boger@canisius.edu 